\title{
Mating-Type and Sexual Differentiation of Phytophthora Colocasiae in Japan
}

Wenzhuo Feng ( $\square$ wenzhuofeng@126.com )

Guizhou University https://orcid.org/0000-0001-6114-2051

\section{Ayaka Hieno}

Gifu University

\section{Kayoko Otsubo}

Gifu University

Haruhisa Suga

Gifu University

Koji Kageyama

Gifu University

\section{Research Article}

Keywords: mating-type, pathogenicity, Phytophthora colocasiae, sexual differentiation, taro

Posted Date: August 10th, 2021

DOI: https://doi.org/10.21203/rs.3.rs-780092/v1

License: (c) (i) This work is licensed under a Creative Commons Attribution 4.0 International License.

Read Full License 


\section{Abstract}

In Japan, Phytophthora colocasiae causes the leaf blight of taro, which has resulted in huge losses since 2015. To investigate the causes of disease persistence and expansion, it is important to clarify the basic properties of this pathogen. We collected in total 317 P. colocasiae isolates from 99 fields in 7 prefectures during 2014 to 2020. The mating-type of each isolate was examined, and two or more isolates which were collected in single fields or taro leaves were selected to analyze the mating-type complexity. We found five kinds of mating types were identified: heterothallic $A 1$ and $A 2$, self-fertile (SF) A1, A2 and A1/A2 types, and a complex and diverse distribution of mating-types was present in one field or leaf. In addition, the stability of each mating-type was analyzed by single hyphae, zoospore and zoosporangium. The results suggested that the SF isolates were shown to be genetically unstable, while heterothallic isolates had a stable property. In the pathogenicity test of different mating-type isolates, heterothallic A1 isolates were less pathogenic than heterothallic A2 and SF isolates. However, there was no relationship between the pathogenicity and the growth rate on culture medium.

\section{Introduction}

Phytophthora colocasiae Raciborski causing a leaf blight of taro (Colocasia esculenta (L.) Schott) was first described in Java in 1900 (Raciborski 1900), and has a wide distribution in tropical and subtropical areas, such as Southeast Asia, many Pacific territories and parts of Oceania. This disease heavily affected taro fields in many locations resulting in losses higher than $30 \%$ of crop production (Jackson and Gollifer 1975; Vasquez 1990). Since the emergence of taro leaf blight in Japan in 2014, it has been spreading rapidly, and in 2015 60\% yield losses occurred in Ehime Prefecture (Kurogi 2017). Moreover, in the other major producing areas for taro, such as Chiba, Miyazaki and Kagoshima prefectures, serious damage was also caused by P. colocasiae. The pathogen even has the ability to infect the edible corms of taro, putting taro storage and seeding at risk.

Phytophthora colocasiae produces asexual spores (zoospores) released from zoosporangia which could actively spread rapidly through water (Brooks 2005). During wet weather, zoosporangia are abundantly produced on the lesions of infected leaves or petioles. Dissemination of the caducous zoosporangia via rain splash is the common dispersal mechanism. A heavy rain or typhoon is usually the main trigger for invasive spread between adjacent taro leaves, plants and fields. Zoosporangia were considered as the most important survival structure of this pathogen in soil (Quitugua and Trujillo 1998), however, it was very fragile in soil environment. Gómez (1925) reported initially that a 3-month survival period could be achieved for the zoosporangia on taro leaf tissue. In both natural and artificially infested soil, the zoosporangia just had only fewer than 21 days of vitality (Gollifer et al. 1979). The longest survival was suggested to be more than 3 months in soil at $-1,500 \mathrm{~J} / \mathrm{kg}$ matric potential, and less than one year in the absence of host (Quitugua and Trujillo 1998). Therefore, related to the long-term recurrence of taro leaf blight, other potential sources and routes of infestation should be considered, in addition to locally produced zoosporangia. 
Oospores produced by sexual reproduction can survive under adverse natural conditions (Sivamani et al. 1987). They are thick-walled, generally globose resting organs that enable as long as 10 years survival in soil and make them an important inoculum source of soil-borne plant diseases (Turkensteen et al. 2000). In Phytophthora species, two main types of sexual breeding systems, heterothallism and homothallism occur. Homothallic Phytophthora spp. produce oospores easily in single culture enabling them to survive in soil (Schmitthenner 1985; Sneh and McIntosh 1974). The heterothallic members depend on the presence of opposite mating types (A1 and A2) for oospore formation (Weste 1983). Phytophthora colocasiaes is heterothallic and the A2 mating type appears to be more widespread (Ann et al. 1986; Tyson and Fullerton 2007; Mellow et al. 2018;). A1 type isolates were only found in Hawaii, USA (Ko 1979), India (Narula and Mehrotra 1980) and Hainan Island of China (Zhang et al. 1994). Lin and Ko (2008) found seven self-fertile A1/A2-type isolates in Taiwan.

Up to now, there is no report about the characteristics and mating types of $P$. colocasiae in Japan. The objectives of this study were to clarify the mating type distribution of this pathogen, and to characterize each mating type, in order to understand their possible survival abilities.

\section{Materials And Methods}

\section{Collection and maintenance of isolates}

A total of 317 isolates were obtained from the diseased taro leaves and petioles of 11, 35, 17, 17, 7, 8 and 4 fields in Kagoshima, Miyazaki, Ehime, Chiba, Saitama, Fukui and Gifu prefectures, respectively, from 2014 to 2020 using selective cornmeal agar containing nystatin, ampicillin, rifampicin, and miconazole (NARM) (Morita and Tojo 2007) (Table 1). All isolates were maintained on corn meal agar (CMA) or potato-dextrose agar (PDA) at $20^{\circ} \mathrm{C}$ in the dark. Eleven isolates including each mating type were randomly selected to be used for single hyphae, zoospore and zoosporangium isolation (Table 2).

\section{Establishment of single hyphae, zoosporangium and zoospore cultures}

The tested isolates are listed in Table 2. Single hyphal tip cultures were produced by transferring one single hypha onto water agar (WA) medium. After two-day incubation at $25^{\circ} \mathrm{C}$, the single hyphae were transplanted onto the NARM medium under an inverted microscope. Finally, the colony from the single hyphae were transferred onto CMA slants. For the single zoosporangium and zoospore cultures, the tested isolate was grown on $\Phi 60 \mathrm{~mm}$ V8 juice agar (V8A) medium ( $1 \mathrm{ml}$ V8 juice, $12.5 \mathrm{mg}$ $\mathrm{CaCO}_{3}, 0.1 \mathrm{~g}$ agar, and $4 \mathrm{~mL}$ distilled water) for one-week incubation at $25^{\circ} \mathrm{C}$. Mycelial agar disks were taken from the margin of the colony on V8A medium using a $5 \mathrm{~mm}$ cork borer. The disks were transferred to sterilized pond and distilled water (1:2) mixture. After one-to two-day incubation at $25^{\circ} \mathrm{C}$, the germinating hyphae from a single zoosporangium or zoospore was transplanted onto NARM medium under an inverted microscope. The colony growing on NARM medium was transferred on to a CMA slant for long-term storage at room temperature.

\section{Mating type tests}


All isolates were grown on $5 \mathrm{~mL}$ V8A plates at $25^{\circ} \mathrm{C}$ in darkness. Two heterothallic isolates obtained from taro fields (EPC201522 and EPC2017Ko1) were selected as standard type strains (A1 and A2). Three V8A plates were prepared for each isolate, one for incubation as single culture, and the other two for pairing it with EPC201522sh1 and EPC2017K01, respectively. Oogonia and oospore formation was examined after incubation for 6 to 14 days. The absence/presence of oospores at the interface between colonies indicated the same/opposite mating type. The single culture plates were examined twice after more than a month to determine whether the isolate was heterothallic or self-fertile based on the formation of oogonia and oospores.

\section{Pathogenicity tests}

Taro ('Ishikawawase') plants were cultivated in a growth chamber at $25^{\circ} \mathrm{C}$ with a $12 \mathrm{~h} \mathrm{light} / 12 \mathrm{~h}$ dark cycle, and fully expanded and detached leaves were used in the experiment. One or two isolates of each mating types from Kagoshima, Miyazaki and Ehime prefecture, respectively, were subcultured to new $\Phi 60$ $\mathrm{mm}$ V8A plates and incubated at $25^{\circ} \mathrm{C}$ in darkness for 3-5 days. The selected leaves were cut into approximately round discs circles of $\$ 50 \mathrm{~mm}$ size. A circular ring-shaped agar block from each culture was excised from the edges of an actively growing colony using two cork borers ( 11.5 and $7 \mathrm{~mm}$ diameter), and placed on each circular leaf. Each inoculated leaf was placed in a $90 \mathrm{~mm}$ Petri dish with 5 $\mathrm{mL}$ sterile distilled water (SDW), and two or three droplets of SDW were dropped into the middle of the agar block. Finally, after covering the plate with the lid, the leaves were incubated at $25^{\circ} \mathrm{C}$ for 3 days in the growth chamber at $25^{\circ} \mathrm{C}$ with a $12 \mathrm{~h}$ light/ $12 \mathrm{~h}$ dark cycle. Then the size of the lesion was measured to assess the virulence. Each experiment was repeated three times.

\section{Results}

\section{Mating-type diversity}

All 317 isolates obtained from 99 fields in 7 prefectures were paired with the standard type strains (A1; EPC201522sh1 and A2; EPC2017K01sh), and also grown as single cultures. By observing the sexual structures in the reacting zone between colonies for pairing and in single cultures, four kinds of mating types were categorized: heterothallic $A 1$ and $A 2$ types, and self-fertile (SF) strains of $A 2$ and A1/A2 mating types (Figs. 1 and 2). Overall, 8 and 200 out of the 317 isolates were heterothallic A1 and A2 mating type strains, respectively, without self-fertilization in single culture. The remaining 109 isolates produced oogonia and oospores in the single cultures. However, 103 and 6 isolates strongly reacted with EPC2017K01sh or both EPC2017K01sh and EPC201522sh1, producing much more oospores in the contact zones than in single cultures. Therefore, these isolates were defined as SF A2 and SF A1/A2 types, respectively (Table 1 ).

The A1 type strains were detected in Kagoshima and Miyazaki Prefectures, especially in Ehime, whereas the A2 type was prevalent in other countries. The A2 type strains were detected in almost all fields of the surveyed prefectures. Although the detection frequency of the SF strains compared to the A2 type strains, they were detected in many fields of all surveyed prefectures except for Saitama Prefecture. In 
Miyazaki and Ehime Prefectures, the fields only with the SF strains were found. The highest detection frequency of the SF strains was in Fukui Prefecture. The mating type ratios did not vary between different years.

\section{Composition of mating types in different taro fields and lesions}

In 64 taro fields, where two or more isolates were collected, mating-type complexity was found. Multiple mating types were present in half of the fields (Table 3). Exclusively heterothallic A2 type strains were found in 30 fields, whereas only SF A2 type strains occurred in three fields. There was no field with exclusive occurrence of A1 type strains. On the other hand, multiple infestation was found in two fields with heterothallic $A 1$ and $A 2$ types, 22 fields with heterothallic $A 2$ and SF $A 2$, two fields with heterothallic $A 2$, SF $A 2$ and $A 1 / A 2$, three fields with heterothallic $A 1, A 2$ and SF A2, and two fields with heterothallic $A 1$, A2, SF A2 and A1A2 (Table 3).

Two to three isolates per leaf were recovered from 13 different leaves in five fields of Kagoshima Prefecture (Table 4). Eight leaves were infected with multiplemating types; one leaf was infected with heterothallic A1 and SF A2, and 7 leaves were infected with heterothallic A2 and SF A2.

\section{Segregation of mating type by purification of the isolates}

To assess the reliability and stability of mating-type, we conducted single hyphal tip, zoosporangium and zoospore isolation from five SF A2 and two SF A1/A2 isolates, and two isolates each of heterothallic A1 and $A 2$ types (Table 5). SF isolates segregated different mating types by the isolations, were re-obtained from all of SF isolates except for the KS17Ai3-2 isolate. On the other hand, the heterothallic isolates of A1 and $\mathrm{A} 2$ types did not segregate different mating types after purification of the isolates.

In the single hyphal tip isolation, heterothallic A2 and SF A2 isolates were obtained from four out of five SF A2 isolates. All single hyphal tip isolates from the KS17Ai3-2 isolate were heterothallic A2 type. In SFA1/A2 isolates, heterothallic A1, and SF A1 and A2 types were obtained from the KS16TaYo2 isolate. whereas the he KS16TaOki5 isolate produced SF A1 and A2 types but not heterothallic type.

In the single zoosporangium isolation, SF A2 isolates strongly trended to produce heterothallic A1 and A2 types. All single zoosporangium isolates form MS28041, KS17Ai3-2 and EPC201534 isolates were heterothallic A2 type. In the EPC201527 isolate, 75\% of the obtained isolates were heterothallic A1 type. The variation of the obtained isolates was also found in SF A1/A2 type. The KS16TaYo2 isolates produced heterothallic $\mathrm{A} 1$ and $\mathrm{A} 2$ types, and SF $\mathrm{A} 1$ and $\mathrm{A} 2$ types.

In the single zoospore isolation, both of SF A2 and A1/A2 types produced heterothallic A1 and/or A2 types. In the MS28101 and EPC201527 isolate, SF A2 type was only obtained.

\section{Comparison of pathogenicity between mating types}


To compare the pathogenicity between mating types, we selected one isolate of each mating type from Kagoshima, Miyazaki and Ehime prefecture, except for SFA1 type, to conduct a pathogenicity test (Table 6). The size of the lesions after inoculation on taro leaves was measured to determine the pathogenicity. Three isolates, one heterothallic A2 isolates from Miyazaki, and two SF A2 isolates from Miyazaki and Kagoshima, respectively, expressed strong pathogenicity and produced about $10 \mathrm{~mm}$ diam. lesions. Five isolates, including that three heterothallic A1 isolates, one SF A2 isolate from Ehime and one SF A1/A2 isolate from Kagoshima, demonstrated a weak or even no pathogenicity producing lesions with less than $3 \mathrm{~mm}$ diameter. The other isolates showed moderate virulence (Table 6).

The growth rates on V8 agar showed variability between the isolates, but no relationship was found between the growth rate and the virulence to taro. Moreover, to evaluate the stability of the mating-type in these isolates during the pathogenicity tests, the recovered isolates from the lesion were tested for mating type. Heterothallic $A 1$ and $A 2$ isolates did not change the mating types (Table 6). Although several SF isolates changed SF A1 and A2 to SF A1/A2 type, and SF A1/A2 to SF A2 type, the characteristic of the self-fertilization did not lose.

\section{Discussion}

In South Asia, P. colocasiae has been mainly heterothallic A2 type (Ann et al. 1986; Tyson and Fullerton 2007; Mellow et al. 2018). The A1 type was major only in Hawaii, USA (Ko 1979) and India (Narula and Mehrotra 1980). In Hainan Island of China, the ratio of A1 and A2 types was 1:1, suggesting that the island could be the center of origin of $P$. colocasiae (Zhang et al. 1994). Self-fertile isolates were found only in Taiwan, China (Lin and Ko 2008). In this study, we examined 317 isolates collected from 99 fields in 7 prefectures of Japan during 6 years. Totally, five kinds of mating-types including heterothallic A1 and A2, SF A1, A2 and A1/A2 were found.. The frequency of the A2 type isolates was $63 \%$, following $33 \%$ of SF A2 ones, while the frequency of A1 type isolates was only $3 \%$. This kind of mating type diversity in $P$. colocasiae has not been reported in any other country.

The taro fields from 7 prefectures were surveyed, including Kagoshima, Miyazaki and Ehime prefectures in south, Fukui and Gifu prefectures in central and Saitama and Chiba prefectures in east. A diversity of the mating-type distribution was found in the southern and central Japan, and a relatively simple matingtype status was showed in eastern Japan. Furthermore, 64 fields and 13 taro leaves were counted to analyze the diversity of mating-types in one field and one leaf, respectively. Both of heterothallic A1 and A2 type existed simultaneously in the same leaves as well as the same fields, and that approximately $35 \%$ isolates were self-fertile, suggesting that the oospore could be a survival structure. Furthermore, these results indicated that there might be multiple sources of infection in one field, and that the possibility of cross-infestation of $P$. colocasiae between adjacent areas would be very high, and importantly the $P$. colocasiae oospores might be widespread in taro fields.

For the mating-type of oomycetes, early researchers suggested that the A1 mating type of oomycetes was relatively stable in their self-progenies, and the A2 type was full of highly variable (Gallegly 1970; Timmer 
1970; Ko 1988). In this study, we randomly selected several isolates of each mating type to check the stability of mating reaction in $P$. colocasiae with single hyphal tip, zoosporangium and zoospore isolation. The SF type isolates were genetically unstable containing both heterothallic and SF types after the isolation. On the other hand, the heterothallic A1 and A2 isolates were stable. Similar reports had been made in several other Phytophthora species. Mortimer et al. (1977) and Fyfe and Shaw (1992) found that SF A1/A2 type of $P$. drechsleri and $P$. infestans could segregate the heterothallic A1 or A2 types during zoospores and vegetative reproduction. A hypothesis was put forward that the mating types of Phytophthora were regulated by molecular configuration of repressor (Ko 1988). Some factors are considered to affect the variation in mating types of Phytophthora during the asexual reproduction, such as aging, fungicide exposure, changes in nutritional conditions, metabolite stimulation of soil microorganisms and mechanical damage (Ann and Ko 1989; Ko 1994, 2007). Overall, the reason of the frequency variation of mating-type in P. colocasiae even Phytophthora genus still needs further study.

We examined 13 isolates to compare the virulence of different mating-types in taro leaves. Determining the size of the lesions caused by heterothallic $A 1$ and $A 2$ isolates, we found the former had a lower virulence than the latter. On the other hand, the virulence of the SF isolates was variable. It could be explained by their genetically unstable, but self-fertilization of SF isolates did not change during inoculation test. In addition, when the growth rates of the isolates tested in the inoculation test were measured, there was no obvious correlation between mating-type and growth rate, and between pathogenicity and growth rate. Moreover, we found some $P$. colocasiae isolates had weak and even no pathogenicity to taro leaves, which could be used as an important material to study the pathogenic mechanism of this pathogen.

Based on the results in the comparison of the stability and the pathogenicity among the mating types, it was hypothesized that an invasion of the SF types contributed to the epidemic of this taro disease in Japan. Because the SF types had two features, the strong pathogenicity and the segregation ability of different mating types included heterothallic $A 1$ and $A 2$ types as well as SF types. The oospore as a survival structure were formed in mating culture between heterothallic $\mathrm{A} 1$ and $\mathrm{A} 2$ type isolates rather than in single culture of the SF type isolates. However, the A1 type was seemed to easily decline in nature because of the week pathogenicity. On the other hand, the SF type isolates was able to segregate heterothallic isolates.

It was clear from this study that the research on the mating-type distribution of $P$. colocasiae was not only helpful to understand the occurrence and development of the disease, but also had profound theoretical significance to the origin, evolution and migration of the pathogen.

\section{Declarations}

\section{Acknowledgments}

We thank T. Matsuda, H. Shibata, S. Yorozu, T. Nakagawa, Y. Murakami, K. Mouri and S. Yamamoto at Ehime Prefectural Government Agriculture, Forestry; S. Kurogi, Y. Kushima, K. Kuno and K. Shimoozono at 
Miyazaki Prefectural Agricultural Experiment Station; and Y. Nishi, K. Nishioka and T. Yuda at Kagoshima Prefectural Institute for Agricultural Development for providing the diseased taro leaf samples and isolates of $P$. colocasiae.

\section{Funding}

This research was supported by grants from the Project of the NARO Bio-oriented Technology Research Advancement Institution (Research program on development of innovative technology), grant no. $29018 C$.

\section{Authors' contributions}

WF, KO and KK performed the experiments and analysed the data. WF, AH, KO, SH and KK conceived, drafted and edited the manuscript. All authors have given approval to the final version of the manuscript.

\section{Conflicts of interest}

The authors declare that the research was conducted in the absence of any commercial or financial relationships that could be construed as a potential conflict of interest.

\section{Availability of data and material (data transparency)}

Not applicable.

\section{Code availability (software application or custom code)}

Not applicable.

\section{Open Access}

This article is licensed under a Creative Commons Attribution 4.0 International License, which permits use, sharing, adaptation, distribution and reproduction in any medium or format, as long as you give appropriate credit to the original author(s) and the source, provide a link to the Creative Commons licence, and indicate if changes were made. The images or other third party material in this article are included in the article's Creative Commons licence, unless indicated otherwise in a credit line to the material. If material is not included in the article's Creative Commons licence and your intended use is not permitted by statutory regulation or exceeds the permitted use, you will need to obtain permission directly from the copyright holder. To view a copy of this licence, visit http://creativecommons.org/licenses/by/4.0/.

\section{References}

1. Ann PJ, Ko WH (1989) Effect of chloroneb and ethazol on mating type of Phytophthora parasitica and $P$. cinnamomi. Bot bull acad sinica 30: 207-210. 
2. Ann PJ, Kao CW, Ko WH (1986) Mating-type distribution of Phytophthora colocasiae in Taiwan. Mycopathologia 93: 193-194. https://doi: 10.1007/BF00443524

3. Brooks F (2005) Taro leaf blight. In: Oomycetes. American Phytopathological Society https ://www.apsne t.org/edcen ter/intro pp/lesso ns/fungi /Oomyc etes/Pages /TaroL eafBl ight.aspx. Cited 4 September 2018

4. Fyfe AM, Shaw DS (1992) An analysis of self-fertility in field isolates of Phytophthora infestans. Mycol res 96: 390-394. https://doi: 10.1016/S0953-7562(09)80958-1

5. Gallegly ME (1970) Genetics of Phytophthora. Phytopathology 60: 135-1. https://doi: 10.1094/Phyto60-1135

6. Gollifer DE, Jackson GVH, Newhook FJ (1980) Survival of inoculum of the leaf blight fungus Phytophthora colocasiae infecting taro, Colocasia esculenta in the Solomon Islands. Ann appl biol 94: 379-390. https://doi: 10.1111/j.1744-7348. 1980. tb03953.x

7. Gómez ET (1925) Leaf blight of gabi. Philipp Agric 14: 429-440

8. Jackson GVH, Gollifer DE (1975) Disease and pest problems of taro (Colocasia esculenta L. Schott) in the British Solomon Islands[J]. Trop Pest Manag 21: 45-53. https://doi:

10.1080/09670877509411487

9. Ko WH (1979) Mating-type distribution of Phytophthora colocasiae on the island of Hawaii. Mycologia 71: 434-437. https://doi: 10.1080/00275514.1979.12021021

10. Ko WH (1988) Hormonal heterothallism and homothallism in Phytophthora. Annu rev phytopathol 26: $57-73$.

11. Ko WH (1994) An alternative possible origin of the A2 mating type of Phytophthora infestans outside mexico. Phytopathology 84: 1224-1227. https://doi: 10.1094/Phyto-84-1224

12. Ko WH (2007) Hormonal regulation of sexual reproduction in Phytophthora. Bot stud 48: 365-375. https://doi: 10.1099/00221287-116-2-459

13. Kurogi S (2017) The occurrences of taro leaf blight caused by Phytophthora colocasiae in Miyazaki prefecture and its control measures (in Japanese). Plant protect 71: 458-462

14. Lin MJ, Ko WH (2008) Occurrence of isolates of Phytophthora colocasiae in Taiwan with homothallic behavior and its significance. Mycologia 100: 727-734. https://doi: 10.3852/08-070

15. Mellow KD, Tyson JL, Fullerton RA, Tugaga A, Maslen-Miller A (2018) Mating types of Phytophthora colocasiae on the island of Upolu, Samoa. New Zeal Plant Prot 71: 289-292. https://doi: 10.30843/nzpp.2018.71.143

16. Morita Y, Tojo M (2007) Modifications of PARP medium using fluazinam, miconazole, and nystatin for detection of Pythium spp. in soil. Plant Dis 91: 1591-1599. https://doi: 10.1094/PDIS-91-12-1591

17. Mortimer AM, Shaw DS, Sansome ER (1977) Genetical studies of secondary homothallism in Phytophthora drechsleri. Arch microbiol111: 255-259. https://doi: 10.1007/BF00549363

18. Narula KL, Mehrotra RS (1980) Occurrence of A1 mating type of Phytophthora colocasiae. Indian Phytopathol 33: 603-604 
19. Quitugua RJ, Trujillo EE (1998) Survival of Phytophthora colocasiae in field soil at various temperatures and water matric potentials. Plant Dis 82: 203-207. https://doi:

10.1094/pdis.1998.82.2.203

20. Raciborski M 1900. Parasitic algae and fungi. Java Batavia Bull 19:189

21. Schmitthenner AF (1985) Problems and progress in control of phytophthora root rot of soybean. Plant Dis 69: 362-368. https://doi: 10.1094/PD-69-362

22. Sivamani E, Anuratha CS, Gnanamanickam SS (1987) Toxicity of Pseudomonas fluorescens towards bacterial plant pathogens of banana (Pseudomonas solanacearum) and rice (Xanthomonas campestris pv. oryzae). Curr sci (Bangalore)56: 547-548

23. Sneh B, Mclntosh DL (1974) Studies on the behavior and survival of Phytophthora cactorum in soil. Revue Canadienne De Botanique52: 795-802. https://doi: 10.1139/b74-103

24. Timmer LW, Castro J, Erwin DC, Belser WL, Zentmyer GA (1970) Genetic evidence for zygotic meiosis in Phytophthora capsici.Am J Bot 57: 1211-1218. https://doi: 10.1002/j.1537-2197. 1970. tb09926.x

25. Turkensteen LJ, Flier WG, Wanningen R, Mulder A (2010) Production, survival and infectivity of oospores of phytophthora infestans. Plant physiol49(6). https://doi: 10.1046/j.1365-3059.2000. 00515. $\mathrm{x}$

26. Tyson JL, Fullerton RA (2007) Mating types of Phytophthora colocasiae from the Pacific region, India and South-east Asia. Australas Plant Dis Notes2: 111-112. https://doi: 10.1071/DN07046

27. Vasquez EA (1990) Yield loss in taro due to Phytophthora leaf blight[J]. J Root Crops16: 48-50

28. Weste G (1983) Population dynamics and survival of Phytophthora. In: Erwin DC, Bartnicki-Garcia S, Tsao PH (eds) Phytophthora: its biology, taxonomy, ecology, and pathology. American Phytopathological Society, St. Paul, pp 237-258

29. Zhang KM, Zheng FC, Li YD, Ann PJ, Ko WH (1994) Isolates of Phytophthora colocasiae from Hainan island in China: evidence suggesting an Asian origin of this species. Mycologia 86:108-112. https://doi: $10.2307 / 3760724$

\section{Tables}

Due to technical limitations, table 1-6 is only available as a download in the Supplemental Files section.

\section{Figures}






Figure 1

Mating-type diversity of Phytophthora colocasiae. Yellow circles show areas with successful mating reactions 



Figure 2

Sexual structures of Phytophthora colocasiae in contact zone between A1 and A2 mating types. A1; EPC201522, A2; EPC2017K01

\section{Supplementary Files}

This is a list of supplementary files associated with this preprint. Click to download.

- Table1.xlsx

- Table2.xlsx

- Table3.pdf

- Table4.pdf

- Table5.xlsx

- Table6.xlsx 